\title{
IncRNA-mRNA competing endogenous RNA network in IR- hepG2 cells ameliorated by APBBR decreasing ROS levels: a systematic analysis
}

\author{
Min Lin ${ }^{1}$, Zhu-Jun Mao ${ }^{\text {Corresp. } 2}$ \\ ${ }^{1}$ College of Basic Medicine, Zhejiang Chinese Medical University, Hangzhou, China \\ 2 College of Pharmaceutical Sciences, Zhejiang Chinese Medical University, Hangzhou, China \\ Corresponding Author: Zhu-Jun Mao \\ Email address: maozhujun0107@zcmu.edu.cn
}

Background: Radix Astragali (Astragalus membranaceus var. mongholicus (Bunge)) and Coptis chinensis $\square$ Coptis chinensis var. angustiloba $\square$ are two commonly prescribed traditional Chinese herbs for diabetes. Astragalus Polysaccharide (AP)and Berberine(BBR) are active ingredients of these two herbs respectively and they are scientifically proved to have immunomodulatory and anti-inflammatory effects. They are also known for their antidiabetic potential by ameliorating insulin resistance(IR).AP and BBR have shown different advantages in treating diabet es according to previous reports. However, very few studies focus on the combined activities of the two potential antidiabetic ingredients.In this study, we discovered that reactive oxygen species (ROS) accumulated in IR-hepG2 cells and APBBR can decrease ROS level in model group significantly. We conjectured that APBBR can ameliorate IR in hepG2 cells by decreasing ROS level. In order to verify this hypothesis, we obtained phenotype and transcriptome information of IR-HepG2 cells and explore the underlying mechanism of the combination of AP and BBR(APBBR) activity on the relationship between ROS change in IR at whole-transcriptome level $\square$ so as to shed new light to efficacy and application of APBBR in treating diabetes. Methods: The IR cell model was established with high-level insulin intervention. Glucose content, HepG2 cell viability as well as ROS level was detected to study the effect of IR-hepG2 cell phenotype. Unbiased genome-wide RNA sequencing was used to investigate alterations in experimental groups. Then GO and KEGG functional enrichment was performed to explore the function and pathway of target genes. Venn analysis found out the differentially expressed IncRNAs that had close relationship with IR and ROS. Finally, we screened out candidate IncRNAs and these target genes to construct interaction network of differentiated IncRNA-miRNA-mRNA by according to the principle of competitive endogenous RNA (ceRNA). 
1 IncRNA-mRNA competing endogenous RNA network 2 in IR-hepG2 cells ameliorated by APBBR decreasing

3 ROS levels: a systematic analysis

4

5

6

7

Min Lin ${ }^{1}$, Zhu-Jun $\mathrm{Mao}^{2 *}$

1 Zhejiang Chinese Medical University College of Basic Medicine, Hangzhou 310053, China

2 Zhejiang Chinese Medical University College of Pharmaceutical Sciences, Hangzhou 311402, China

Corresponding Author:

Zhu-Jun $\mathrm{Mao}^{2}$

548 Bin Wen Road, Hangzhou, China 310053.

Email address: maozhujun0107@,163.com

\section{Abstract}

Background: Radix Astragali (Astragalus membranaceus var. mongholicus (Bunge)) and Coptis chinensis (Coptis chinensis var. angustiloba) are two commonly prescribed traditional Chinese herbs for diabetes. Astragalus Polysaccharide (AP)and Berberine (BBR) are active ingredients of these two herbs respectively and they are scientifically proved to have immunomodulatory and anti-inflammatory effects. They are also known for their antidiabetic potential by ameliorating insulin resistance(IR).AP and BBR have shown different advantages in treating diabetes according to previous reports. However, very few studies focus on the combined activities of the two potential antidiabetic ingredients. In this study, we discovered that reactive oxygen species (ROS) accumulated in IR-hepG2 cells and APBBR can decrease ROS level in model group significantly. We conjectured that APBBR can ameliorate IR in hepG2 cells by decreasing ROS level. In order to verify this hypothesis, we obtained phenotype and transcriptome information of IR-HepG2 cells and explore the underlying mechanism of the combination of AP and BBR(APBBR) activity on the relationship between ROS change in IR at whole-transcriptome level so as to shed new light to efficacy and application of APBBR in treating diabetes.

Methods: The IR cell model was established with high-level insulin intervention. Glucose content, HepG2 cell viability as well as ROS level was detected to study the effect of IRhepG2 cell phenotype. Unbiased genome-wide RNA sequencing was used to investigate alterations in experimental groups. Then GO and KEGG functional enrichment was performed to explore the function and pathway of target genes. Venn analysis found out the differentially expressed IncRNAs that had close relationship with 
IR and ROS. Finally, we screened out candidate IncRNAs and these target genes to construct interaction network of differentiated IncRNA-miRNA-mRNA by according to the principle of competitive endogenous RNA (ceRNA).

Results: The biochemical experiments showed that APBBR administration could improve the proliferation activity of IR-HepG2 cells and decrease ROS level in model cells. The GO and KEGG functional enrichment analyses demonstrated several mRNAs remarkably enriched in biological processes and signaling pathways related to ROS production and IR progression. Interaction network suggest that APBBR ameliorates IR in HepG2 cells by regulating the expression of multiple genes and activating relevant signaling pathway to decrease ROS level. Thus, we demonstrated that APBBR ameliorated IR in hepG2 cells via ROS-dependent pathway.

\section{Introduction}

Transcriptome sequencing in various organisms has revealed that abundant transcription derived from human transcriptome generates a large proportion of noncoding RNAs (ncRNAs). Increasing evidence have shown the critical regulatory potential of ncRNAs in biological processes. The ncRNAs are classified into two categories according to their length: long non-coding RNAs (IncRNAs) with a length of more than 200 nucleotides and short noncoding RNAs (18 to 200 nucleotides) respectively (Li et al., 2019).IncRNA accounts for 68\% of ncRNAs (lyer et al., 2015),but they were considered "junk RNA" in the genome because they could not encode proteins (Zhang et al., 2019). However, recent studies have shown that IncRNA exert critical roles in regulating biological processes through comprehensive mechanisms , including genetic imprinting, immune response, tumorigenesis, cellular development and metabolism (Liyanage \& Ganegoda, 2017). LncRNAs are also involved in the regulation of glucose and lipid metabolism in the liver, and their abnormal expression may be involved in the development of type 2 diabetes mellitus(T2DM) (Eslam, Valenti \& Romeo, 2018).

Insulin resistance (IR)refers to a physiological condition in which target tissue such as fat, liver and muscle are unable to use insulin effectively. The metabolism of substances in the body is almost all regulated by insulin (Williams \& Olefsky, 1990). Once IR occurs, the metabolism of sugars, lipids and proteins will be disturbed. The physiological regulation of insulin is mainly carried out by combining with the insulin receptors on the cells of various tissues. Any defect in the signal transmission in the process may affect the normal physiological regulation process of insulin and thus cause the occurrence of IR. IR degree in different tissues is specific, which makes its mechanism complex.

Reactive oxygen species (ROS) is a collective term to include oxygen-containing reactive species (Li, Jia \& Trush, 2016). It is a significant contributor to the cell and 
88

89

90

91

92

93

94

95

96

97

98

99

100

101

102

103

104

105

106

107

108

109

110

111

112

113

114

115

116

117

tissue dysfunction in diabetes and the progression of complex diabetic complications(Newsholme et al., 2007). The increased ROS formation may cause oxidative stress, which plays a significant role in the development of hepatic IR (Liu et al., 2017). HepG2 cells are ideal model for studying hepatic IR pathogenesis and action mechanism of hypoglycemic drugs. The number of insulin receptors on the surface of HepG2 cells decreases with high level insulin intervention (Williams \& Olefsky, 1990). At present, the underlying molecular mechanisms and regulation of ROS change in IRHepG2 cells remains poorly understood.

Astragalus Polysaccharide (AP) is the main effective ingredient extracted from the Chinese herb Radix Astragali (Astragalus membranaceus var. mongholicus (Bunge)), which has the potential activity of antioxidant effects (Fu et al., 2018).Berberine (BBR) is an isoquinoline extracted from Coptis chinensis (Coptis chinensis var. angustiloba), which has many pharmacological activities such as antimicrobial, anti-diarrheal, reducing glucose and cholesterol, anti-tumor and immunosuppression. The plant names have been checked with www.theplantlist.org. Both of these two herbs have been used to treat diabetes for thousands of years in Traditional Chinese Medicine, study showed that the combination of Coptidis rhizoma, Astragali radix and Lonicera japonica(Lonicera alba L.) has a synergistic effect by increasing insulin sensitivity and ameliorating IR (Yang et al., 2017). In addition, it has been verified that AP and BBR could promote glucose up-take and improve carbohydrate metabolism respectively with different characteristics (Wang et al., 2019). Our previous study results showed that AP and BBR used together at a ratio of 1:1 could promote the basic secretion ability of IR-INS-1 cells model significantly, and showed a synergistic effect in diabetes treating (Mao et al., 2017). The study found has been applied for a patent, the application number: CN201810266347.9, publication / announcement number: CN108478591A. However, the cellular and molecular compatibility mechanism responsible for APBBR in attenuating IR remains unclear.

Additionally, there were few studies to identify key genes and pathways involved in ROS change in IR-HepG2 cells. Spurred by the development of deep sequencing technology, we are allowed to investigate the mechanisms of hepatic IR at the whole-transcriptome level. In the present study, we used high-throughput RNA-seq technology to explore the potential mechanism underlying hepatic IR at whole-transcriptome level by analyzing changes in the global gene expression profile in normal, IR and APBBR-treated HepG2 cells for the first time. First, differentially expressed genes (DEGs), related gene ontology (GO) and pathways were determined. Subsequently, gene act, pathway act and co-expression network were constructed to further explore the role of the ROS and 
118 IR related genes and pathways, which could shed new light to the underlying

119 mechanisms of ROS and IR and therapeutic applications of APBBR in treating diabetes.

120 Materials \& Methods

121 HepG2 cells cultured

122

HepG2 cells (Cell Bank of the Chinese Academy of Sciences, Shanghai, China)

123 were cultured in 1640 medium (Hyclone, Beijing, China) containing 10\% fetal bovine

124

125

126

127

128

129

130

131

132

133

134

135

136

137

138

139

140

141

142

143

144

145

146

147

148

149

150

151

152

153

154

155

156

serum (FBS, Hyclone, Beijing, China) and $1 \times$ streptomycin in a $37{ }^{\circ} \mathrm{C} 5 \mathrm{CO} 2$

saturated humidity incubator. The normally cultured HepG2 cell lines in log phase were centrifuged at $100 \mathrm{grpm}$ for $5 \mathrm{~min}$. 20000cells/well were plated in a 96-well plate and incubated at $37^{\circ} \mathrm{C}$.

\section{Administration}

Insulin (Gibco, NY, USA) was diluted to a final concentration of $10^{-6} \mathrm{~mol} / \mathrm{L}$ according to our preliminary experiment. $200 \mu$ of the insulin preparation was added into each well for the model group and $200 \mu \mathrm{l}$ of complete media was added for the control group. Culture was performed in $37^{\circ} \mathrm{C}, 5 \% \mathrm{CO}_{2}$ and saturated humidity incubator. The supernatant of the corresponding medium was collected after $48 \mathrm{~h}$ by centrifugation at $3000 \mathrm{r} / \mathrm{min}$ for $5 \mathrm{~min}$ and stored at $-80{ }^{\circ} \mathrm{C}$ for use.

\section{Cell groups}

Control, Model, APBBR

To examine whether the APBBR had e $\square$ ect on HepG2 cells, HepG2 cells assigned to a control group(Control), and the molding cells were assigned randomly into IR model group(Model), Model + 1mg APBBR group (1mg APBBR group), Model $+5 \mathrm{mg}$ APBBR group ( $5 \mathrm{mg}$ APBBR group), Model + $10 \mathrm{mg}$ APBBR group (10 mg APBBR group) ; Model + $20 \mathrm{mg}$ APBBR group (20 mg APBBR group) ; Model $+40 \mathrm{mg}$ APBBR group (40 mg APBBR group). APBBR was administered at a 1:1 mass ratio of AP:BBR. After successful establishment of the IR model, different concentrations of APBBR were added. (The mass ratio of AP to BBR was 1:1,Astragalus Polysaccharide was provided by Lot No. C11M7Y10255, Shanghai Yuanye Biotechnology Co., Ltd.Shanghai, China. Assay $\geqslant 98 \%$; Berberine was provided by Lot No.160528, Beijing Century Aoko Biotechnology Co., Ltd. Beijing, China. HPLC $\geqslant 98 \%$ ); Control and Model group was cultured in normal medium, each well system was $2 \mathrm{ml}$, and the action time was $48 \mathrm{~h}$.

\section{Study on the effect of IR-hepG2 cell phenotype}

Glucose content determination

The glucose content determination reagent(RSBIO, Shanghai, China) was balanced at room temperature, the reagent working solution was configured, and $20 \mathrm{ml} \mathrm{R} 1$ reagent and $20 \mathrm{ml} \mathrm{R2}$ reagent were mixed well in the same amount. The EP tubes were marked as a blank tube, a calibration tube, a quality control tube and a sample tube accordingly. There are six tubes in every group ,each of which is added with 1000 ul working fluid. 
157 Then blank tube was added with 10ul distilled water; calibration tube was added with

158 10ul calibration product; quality control tube was added with 10ul quality control product

159

160

161

162

163

164

165

166

167

168

169

170

171

172

173

174

175

176

177

178

179

180

181

182

183

184

185

186

187

188

189

190

191

192

193

194

195

; sample tube was added with $10 u$ samples. After full mixing, it was placed in $37^{\circ} \mathrm{C}$ water bath for 15 minutes. The $200 u$ of each tube was transferred to 96 -well plate, and the absorbance was measured at the wavelength of $505 \mathrm{~nm}$.

Detection of HepG2 cell viability by CCK8

The original culture medium was abandoned and the drug was added according to the above administration concentration. The system of each well was $200 \mu \mathrm{I}$ and the effect was $48 \mathrm{~h}$. The experiment was repeated three times. After drug action, each well was added with $10 \mu \mathrm{L} \mathrm{CCK8}$ detection solution(UNOCI , Hangzhou, China). The medium was set as a blank control well, and light-avoidance reaction was conducted at $37^{\circ} \mathrm{C}$ for $2 \mathrm{~h}$ Optical density (OD) was measured at $450 \mathrm{~nm}$ and $650 \mathrm{~nm}$. The results were calculated as follows: cell survival rate $(\%)=$ OD value of experimental group / OD value of non-drug group $\times 100 \%$.

Detection of ROS of HepG2 cells by flow cytometry

The cryopreserved tube contianing $1.5 \mathrm{~mL}$ cells was taken out from the liquid nitrogen tank and quickly placed in water bath at $37^{\circ} \mathrm{C}$ for about $2 \mathrm{~min}$. The cell suspension in the tube was moved into a $15 \mathrm{~mL}$ centrifuge tube, to which $5 \mathrm{~mL}$ complete medium was added, and centrifugal at $300 \times \mathrm{g}$ for $5 \mathrm{~min}$ at room temperature. After removing the supernatant, cells were resuspended with a moderate amount of complete medium heavy precipitation, inoculated in a $10 \mathrm{~cm}$ petri dish, added with complete medium to 10 $\mathrm{mL}$, and cultured again in $37^{\circ} \mathrm{C}$ and $5 \% \mathrm{CO}$, saturated humidity. $1 \mu \mathrm{L}$ ROS probe (Beyotime, Shanghai, China) was added to the resuscitated cells in the proportion of 1:1000, mixed, incubated at $37{ }^{\circ} \mathrm{C}$ for $20 \mathrm{~min}$, and oscillated several times per $5 \mathrm{~min}$. After 5-centrifugation, cell precipitation was collected, $1 \mathrm{~mL}$ PBS was resuscitated, and centrifuged at $500 \times \mathrm{g}$ for $5 \mathrm{~min}$. $1 \mathrm{~mL}$ PBS was resuspended to be measured. A negative control group was set up and treated in the same way without adding the probe. FITC signal was detected by flow cytometry, FITC signal was detected by FL-1A channel, PI signal was detected by FL-2A channel.

\section{RNA library construction and sequencing}

Total RNA was extracted using Trizol reagent (Invitrogen, CA, USA) following the manufacturer's procedure. The total RNA quantity and purity were analysis of Bioanalyzer 2100 and RNA 6000 Nano LabChip Kit (Agilent, CA, USA) with RIN number >7.0. Approximately $10 \mathrm{ug}$ of total RNA representing a specific adipose type was used to deplete ribosomal RNA according to the manuscript of the Epicentre Ribo-Zero Gold Kit (Illumina, San Diego, USA). Following purification, the poly(A)-or poly(A)+ RNA

Peer] reviewing PDF | (2019:08:40702:2:0:NEW 4 Jan 2020) 
196

197

198

199

200

201

202

203

204

205

206

207

208

209

210

211

212

213

214

215

216

217

218

219

220

221

222

223

224

225

226

227

228

229

230

231

232

233

234

235

fractions is fragmented into small pieces using divalent cations under elevated temperature. Then the cleaved RNA fragments were reverse-transcribed to create the final cDNA library in accordance with the protocol for the mRNA-Seq sample preparation kit (Illumina, San Diego, USA), the average insert size for the paired-end libraries was $300 \mathrm{bp}( \pm 50 \mathrm{bp})$. And then we performed the paired-end sequencing on an Illumina Hiseq 4000 at the (LC Bio, China) following the vendor's recommended protocol (150 bp x 2).

Genome Mapping and Transcripts Assembly

Firstly, Cutadapt (version 1.10) was used to remove the reads that contained adaptor contamination, low quality bases and undetermined bases. Then sequence quality was verified using FastQC (http://www.bioinformatics.babraham.ac.uk/projects/fastqc/). We used Bowtie (version 2) and Tophat (version 2.0) to map reads to the genome (GRCh38)of IR- HepG2 cells. The mapped reads of each sample were assembled using StringTie (version 1.3.0). Then, all transcriptomes from IR- HepG2 cells were merged to reconstruct a comprehensive transcriptome using perl scripts. After the final transcriptome was generated, StringTie and Ballgown[R package]was used to estimate the expression levels of all transcripts.

LncRNA identification

First of all,transcripts that overlapped with known mRNAs and transcripts shorter than 200 bp were discarded. Then we utilized CPC [0.9-r2], $\mathrm{CNCl}$ [2.0] to predict transcripts with coding potential. All transcripts with CPC score $>-1$ and $\mathrm{CNCl}$ score $>0$ were removed. The remaining transcripts with class code $(i, j, o, u, x)$ were considered as IncRNAs. (i) a transfragfalling entirely within a reference intron(intronic); (j) potentially novel isoform or fragment at least one splice junction is shared with a reference transcript; (o) generic exonic overlap with a reference transcript; (u) unknown, intergenic transcript(intergenic); (x) Exonic overlap with reference on the opposite strand (antisense).

Target gene prediction, functional and property analysis of differentially expressed mRNAs and IncRNAs

StringTie was used to perform expression level form RNAs and IncRNAs by calculating fragments per kilobase of exon per million fragments mapped (FPKM). The differentially expressed mRNAs and IncRNAs were selected with |log2(fold change)|>1 and with statistical significance $(P$ value $<0.05)$ by $R$ package Ballgown To predict the possible functions of the target mRNAs and to explore the pathways in which they participate, target mRNAs were further studied using the GO (http://www.geneontology.org) and KEGG (http://www.genome.jp/kegg) databases. The $P$ value $<0.05$ and llog2(fold change) $\mid \geqslant 1$ were defined as statistically significant. The characteristics such as gene 
236 lengths, transcript lengths, IncRNA types, exons number and isoforms number of 237 differentially expressed mRNAs and IncRNAs were analyzed and compared according 238 to the reference genome annotation and databases. The ORF lengths of differentially 239 expressed mRNAs and IncRNAs were obtained by genescan (Burge \& Karlin,

240 1997)prior to analysis and comparison.

241

242

243

244

245

246

247

248

249

250

251

252

253

254

255

256

257

258

259

260

261

262

263

264

265

266

267

268

269

270

271

272

273

274

275

ceRNA network construction

Using existing miRNA target prediction methods, IncRNA-miRNA-mRNA interactions were identified. TargetScan 5.0 software (http://www.targetscan.org/) and miRanda 3.3a (http://www.microrna.org/microrna/home.do) were simultaneously used to predict the IncRNAs and 3'UTR sequences of mRNAs as miRNA targets. Based on the ceRNA hypothesis, we also identified putative IncRNA-miRNA integrations using TargetScan and Miranda, these IncRNAs are regarded as competing endogenous RNAs(ceRNA) to bind miRNA competitively and affect mRNA (miRNA target gene) expression indirectly. Combining the two data sources, we got miRNA-IncRNA -mRNA interactions. In order to observe the relationship of the triplet in the IR and identify the APBBR-treatment related IncRNAs. We also mapped 3 IR-associated mRNAs and 7 differential expressed IncRNAs shows opposite tendency before and after APBBR treatment into global triple network. The mutual interaction network of differentially expressed genes and the coreregulatory network of IncRNAs - miRNAs -target genes were mapped via Cytoscape software (V. 3.2.1).

\section{Statistical analysis}

All experimental data were performed using SPSS 23 software (IBM SPSS, Armonk, NY, USA) and R package 3.3.0. All graphical values were presented as the means \pm SEM. Student's $t$ test was used to evaluate the statistical differences between two groups. Data among three groups were analyzed with one-way ANOVA followed by LSD when equal variances assumed, and Dunnett's-T3 when equal variances not assumed. A value of $P<0.05$ was statistically significant different. Figures were drawn by GraphPad Prism 6.02 and Adobe Illustrator CS6.

\section{Results}

High-dose insulin induced decrease of glucose content in IR-HepG2 cells The results of intracellular glucose content determination in HepG2 cells are shown in Fig.1A.Compared to control group, the glucose content in model group decreased significantly $(\triangle \triangle P<0.01$.)

\section{APBBR administration increased the survival rate of IR-HepG2 cells}

CCK8 assay was used to detect the proliferation activity of HepG2 cells, as shown in Fig.1B. The cell survival rate was significantly increased in $10 \mathrm{mg}$ and $20 \mathrm{mg}$ APBBR group compared to model group $\left({ }^{* *} P<0.01\right)$. The optimal dosage of APBBR was $10 \mathrm{mg}$ and $20 \mathrm{mg}$. For convenience, $10 \mathrm{mg}$ was used in the subsequent experiments. 
276

277

278

279

280

281

282

283

284

285

286

287

288

289

290

291

292

293

294

295

296

297

298

299

300

301

302

303

304

305

306

307

308

309

310

311

312

313

314

315

\section{APBBR decreased ROS level in IR-HepG2 cell model}

The ROS content in HepG2 cells detected by flow cytometry were shown in Figure.1C. $\Delta P<0.05$ and ${ }^{\Delta} P P<0.01$, compared with those in the control group; ${ }^{*} P<0.05$ and ${ }^{* *} P<0.01$ compared with that of the model group. The results showed that the level of ROS in IR-HepG2 cells increased significantly, and APBBR could decrease the level of ROS in IR-HepG2 cell model.

\section{Expression profiles of mRNAs in experimental groups and ROS related mRNAs} Total RNA and whole transcriptome sequencing data (mRNA, miRNA, IncRNA) were acquired from qualified biospecimens (see "Methods"). The Illumina Hiseq2500 platform was used to obtain mRNA, IncRNA and miRNA data. As a result of this analysis, we detect thousands of genes. To determine the regulation of mRNA expression, we performed an unsupervised clustering analysis of the significantly regulated genes in IR and APBBR cells. The EBseq algorithm was applied to filter the differentially expressed genes(DEGs) according to the criteria of a|log2 (fold change) $\mid \geq 1$ and a $P$-value $<0.05$.

There were 157 genes whose changes met the criteria. 50 genes were significantly and differentially expressed in Model group relative to Control group, with 24 up-regulated genes and 26 down-regulated genes. 107 genes were significantly altered in APBBR group compared with that in Model group, with 56 genes up-regulated and 51 genes down-regulated Fig.2A. The Volcano plots for mRNAs are showed as Fig. 2B,C. The heatmaps for DEGs are showed as Fig. 2D, E. To analyze the function of these DEGs, we next conducted GO Fig. 2F,G. and KEGG pathway analysis on these genes Fig. $2 \mathrm{H}$. DEGs in Model vs. Control were largely involved in lysine degradation, RNA degradation, taurine and hypotaurine metabolism, sulfur relay system, ascorbate and aldarate metabolism, AMPK signaling pathway. DEGs in APBBR vs. Model were involved in Protein processing in endoplasmic reticulum, spliceosome, systemic lupus erythematosus, steroid hormone biosynthesis, tryptophan metabolism ,MAPK signaling pathway. According to GO and KEGG pathway results as well as previous reports of IR, we notice that genes such as SCD, DUSP5 and PLK3were quite important for ROS development ,which may result in IR Fig. 2 I.

\section{Differentially expressed IncRNAs in experimental groups and IncRNAs that} participates in APBBR treatment

A total of 66980 IncRNAs were annotated in this study. In this study, 12,962 IncRNAs were first annotated as known IncRNAs (database: GRCh38 Ensembl v88). The 32433 newly identified IncRNAs included 17508 IncRNAs (category code u), 85 antisense IncRNAs, 526 intron IncRNAs, and 3466 other IncRNAs. Almost all known IncRNAs are distributed on each chromosome, but those universal exon IncRNAs and reference IncRNA transcriptors (category code o) do not show significant chromosome location preference.Fig.3A.

Peer) reviewing PDF | (2019:08:40702:2:0:NEW 4 Jan 2020) 
From the RNA-seq results, a total of 521 IncRNAs were detected with $P<$

319 0.05.Compared to Control , 384 IncRNAs were detected to be differentially expressed in Model (89 up regulated and 295 down regulated).Compared to Model, 196 IncRNAs were identified to be differentially expressed in APBBR (113 up regulated and 83 downregulated) Fig.3B. The Volcano plot for IncRNAs are showed respectively as Fig.3C,D.Heatmap for top 100 differentially expressed IncRNAs in different groups are showed as Fig.3E,F.

324

325

326

327

328

329

330

331

332

333

334

335

336

337

338

339

340

341

342

343

344

345

346

347

348

349

350

351

352

353

354

355

If APBBR can improve IR, it is necessary to ensure that the IncRNA expression trend is exactly opposite in both Model vs. Control and APBBR vs. Model. That is to say, we should find out genes decreased in Model group compared to Control group but increase in APBBR group contrasted with Model group (decrease-increase type) and genes increased in Model group compared to Control group but decreased in APBBR group in contrast to Model group (increase-decrease type).According to this principle, Venn analysis was additionally applied to learn the IncRNAs that participates in the exertion of APBBR treatment e $\square$ ect, including increasing/decreasing type and decreasing / increasing type. We found two of them(CTD-260009.2, MIR4435-2HG) can be reversed by APBBR in the 295 downregulated genes following IR. Similarly, APBBR treatment tend to reversed 5(RP5-1057I20.5,CTD-3014M21.1,HOXBAS3,LAMA5-AS1,CTD-2517M22.14) of the 89 upregulated IncRNAs following IR Fig.3G,H.

\section{Comparative characteristics analysis of mRNAs and IncRNAs}

To investigate the difference between differentially expressed mRNAs and IncRNAs in genomic characteristics, transcript lengths, the gene lengths, exons number, ORF lengths, isoforms number were analyzed. FPKM data shows that the abundance of IncRNA is lower than that of mRNA in RNA-seq samples, indicating that IncRNAs exhibited a notable bias toward fewer transcript isoforms Fig.4A,B.In addition, we found that the length of IncRNA is usually shorter than that of mRNA Fig.4C. For example, most IncRNAs have less than six exons, while mRNA have more exons and exon numbers distributed over a wider range. Some mRNA have as many as 30 exons Fig.4D.LncRNAs also have shorter (60-90 nucleotide) ORF than mRNA, while most mRNAs have more than 500 nucleotide ORF Fig.4E,F.

\section{Construction of a IncRNAs-miRNA-mRNA network}

To systematically explore the influence of dynamic changes in ceRNA regulation on gene expression related to IR and ROS in Normal, Model and APBBR-treated hepG2 cells. we constructed a ceRNA network, integrating matched expression profiles of IncRNAs, miRNAs and mRNAs. Target genes were selected according to the results of GO or KEGG pathway analysis or according to previous reports of ROS-associated genes that may lead to IR, and then the global miRNA-mediated ceRNA network was 
356

357

358

359

360

361

362

363

364

365

366

367

368

369

370

371

372

373

374

375

376

377

378

379

380

381

382

383

384

385

386

387

388

389

390

391

392

393

394

constructed (Fig.5). In the IncRNA-miRNA-mRNA predicted interaction network, seven IncRNAs and three mRNAs had the same expression trend (belonging to the increasedecrease type/decrease-increase type). Twenty-five miRNAs were predicted to be possible target genes for regulation.

\section{Discussion}

Systemic or local IR occurs when insulin target organs or tissues become less sensitive and responsive to endogenous or exogenous insulin (Semenkovich, 2016).IR refers to the weakened response of tissues to circulating insulin (Archer, Von Schulze \& Geiger, 2018), it mainly take place in skeletal muscle cells, fat cells and liver cells, it can also occur in vascular endothelium and islet beta cells (Dontsov \& Vasil'eva, 2016). IR involving multiple molecules and signaling mechanism, including insulin and its antagonist, insulin receptor substrates, phosphatidyl inositol 3 kinase (PI3K), glucose transporter gene and protein, mitogen-activated protein kinase (MAPK), etc (Seino et al., 2010). It has been proved that IR is the common pathological basis of abnormal glucose and lipid metabolism of essential hypertension, T2DM,coronary heart disease, hyperlipidemia and other diseases. (Tan, Sasagawa \& Mori, 2017; Otto et al., 2019).

ROS include superoxide ionon ( $\left(\mathrm{O}^{2-}\right)$, hydroxyl radical $\left(\mathrm{OH}^{-}\right)$and hydrogen peroxide $\left(\mathrm{H}_{2} \mathrm{O}_{2}\right)$, among which $\mathrm{O}^{2-}$ has high activity and cytotoxicity and is mainly produced by aerobic microorganisms (Newsholme et al., 2016).If the cell antioxidant system fails to suppress ROS, ROS would react with cell macromolecules, leading to lipid peroxidation, causing cell DNA damage, which may result in oxidative stress and oxidative damage to the cell(Chattopadhyay et al., 2015). Oxidative stress is also known as ROS imbalance, where reactive oxygen species produced by the body exceeds their antioxidant capacity, leading to excessive generation of free ROS or dysfunction of antioxidant system (Meex, Blaak \& van Loon, 2019).Oxidative stress can damage critical cellular macromolecules and stimulate various stress sensitive intracellular pathways such as cJun, N-terminal kinase, ERK1/2 and the NF- $\mathrm{k}$ B (Keane et al., 2015). It can also produce chronic low-grade inflammatory reaction (Klaunig et al., 2011). It is increasingly accepted that oxidative stress is a significant contributor to the progression of IR.

It is noteworthy that IR also produces excessive free radicals and superoxides through proton electrochemical gradient, which destroys the antioxidant defense ability of various tissues (Val qko et al., 2007), and also affects the expression of glucose transporter-GLUT1 and antioxidant defense function, thus increasing oxidative stress (Gonzalez-Menendez et al., 2018).-

Astragalus Polysaccharide(AP)and berberine (BBR) have been reported to have antidiabetic properties (Meng et al., 2018; Jiang et al., 2015).AP can modulate the 
395

396

397

398

399

400

401

402

403

404

405

406

407

408

409

410

411

412

413

414

415

416

417

418

419

420

421

422

423

424

425

426

427

428

429

430

431

432

433

434

insulin-initiated phosphorylation cascades in a similar manner as metformin in HepG2/IR cell model (Sun et al., 2019).BBR is reported to demonstrate an excellent activity with oxidative stress and inflammation through a variety of signaling pathways including NF- $\mathrm{K}$ B, AMPK, Nrf2 / HO, JNK, C-Jun and MAPKs pathways and various kinases in cell (Ma et al., 2018), which indicates its IR-improving potential. However, the molecular mechanisms for this action are not fully clarified. Our study showed that APBBR can improve the proliferation activity and decrease the level of ROS in IRHepG2 cell model, suggesting the antioxidant mechanism of APBBR and APBBR may be a stable and reliable means to attenuate IR and its adverse metabolic consequences in HepG2 cells.

RNA-seq analysis is a powerful approach for investigating underlying molecular mechanisms of complex biological processes (Han et al., 2014).NcRNAs include miRNAs and LncRNAs. LncRNA is a hotspot in the field of biological medicine, its important function in the cell has been widely accepted as the successor of another wave of research followed miRNAs. It was found that the expression of IncRNA in human pancreatic island cells had exceeded 1100 species (Moran et al., 2012).Various miRNAs and IncRNAs have been found to be associated with IR and intensive studies on ncRNAs had shed light on understanding the pathogenesis of IR (Esguerra et al., 2011; Davalos et al., 2011; Zeggini et al., 2007). Recently, competing endogenous RNA networks have been reported as a novel mechanism to set up an extensive regulatory network in a post-transcriptional layer. According to the "ceRNA hypothesis" , IncRNAs competitively interacted with the miRNAs and thereby "talk" to mRNAs through microRNA response elements (MREs) (Phelps et al., 2016). Based on this reasoning, we constructed a global triple network , in which IncRNA and mRNA from a triple sharing the same miRNA.

To the best of our knowledge, this was the first study to detect genome-wide transcriptome of IR-HepG2 cell to predict potential IncRNA-mediated networks in APBBR attenuating IR at the molecular level. In the present study, we found that compared with Control group, 384 DEIncRNAs and 50 DEGs were present in Model group and there were 196 DEIncRNAs and 107 DEGs in APBBR vs. Model. GO and KEGG pathway analyses showed the potential functions of the DEGs involved in the mechanism of APBBR treatment; and the ceRNA analysis identified several potential IncRNA/miRNA/mRNA interaction networks that might ameliorate the development of $I R$. The sequencing depth involves mRNA, miRNA and IncRNA, which allowed us to detect di $\square$ erences in gene expression at the transcriptome level and predict the regulatory mechanisms that may mediate ROS changes by ceRNA. These results suggest more comprehensive perspectives to understand IR progress and explore mechanisms of APBBR treatment. Firstly, we select the candidate mRNA according to 
435 GO and KEGG pathway analyses and previous relevant studies of ROS and IR.

436 Secondly, for validation, we chose the IncRNAs that exhibited opposite variation trend

437 before and after APBBR treatment. Venn analysis was additionally applied to learn the

438 possible marker that participates in the process of APBBR's improving IR.

439

440

441

The ceRNA network offers considerable clues for understanding the key roles of

442 ceRNA-mediated gene regulatory networks in ROS genesis and APBBR regulation

443 mechanism as well as further detail analysis of biological function of IncRNA. From the ceRNA network, we identified a substantial amount of cross-talk within the non-coding

444 RNAs, in which mRNAs were co-expressed with candidate IncRNAs mediated by miRNAs and subsequently formed a complex network. According to this analysis, we discovered 7 IncRNAs involving in the process of APBBR's improving IR. Of which, the IncRNA MIR4435-2HG decreased expression in Model group but increased in APBBR group, connecting many mRNAs that may ameliorate IR according to GO enrichment analysis and pathway analysis, and it could directly interact with aberrant miRNA expression contributes to IR. For instance, miR-320 is reported to promote IR in high glucose treated adipocytes and anti-miR-320 oligo was found to regulate IR in adipocytes by improving insulin-PI3-K signalling pathways (Ling et al., 2009). In our study, miR-320 increased expression in Model group but decreased after APBBR treatment. According to the ceRNA theory, there may be a triplet that contained MIR4435-2HG, miR-320 and the downstream target mRNAs, the IncRNA could sponge the miRNA and change the expression of target mRNAs. We found that PLK3 and DUSP5 tend to be the target mRNAs in the network. Polo-like kinase 3 (PIk3) is a serine/threonine protein kinase of the Polo-like kinase family, which is critical for tumor suppression and stress responses (Barr, Sillje \& Nigg, 2004). Moreover, up-regulation of Dusp5 (a tumor suppressor) is able to negatively regulate the MAPK signaling pathway (Zhang et al., 2014). MAPK plays a critical role during the process of inflammation and IR (Zhou et al., 2018), the negative regulation of MAPK might ameliorate inflammation and activate insulin signaling in liver. That is to say, miR-320 may cause IR by activating the MAPK pathway to increase hepatic oxidative stress and APBBR may decrease ROS 466 level in IR-HepG2 cells by negatively regulating miR-320.

IR can play a role in lipid metabolism disorders in the body and promotes lipid deposition in liver. We notice that the mRNA related to lipid metabolism SCD increase significantly in IR vs. Control and it tend to be decreased in APBBR vs. IR. SCD encodes an enzyme involved in fatty acid biosynthesis, primarily the synthesis of oleic acid. The enzyme is also important in the conversion of polyunsaturated fatty acids (PUFAS) to monounsaturated fatty acids (MUFAS). The PUFAs are the major cellular 473 target of ROS and readily provide an extractable proton to oxygen-free radicals (UshioFukai \& Alexander, 2004). The decreased expression of SCD after APBBR treatment 
475 may decrease ROS level in IR-HepG2 cells and thereby attenuating IR. These results 476 are consistent with previous studies that SCD has been shown to be over expressed in 477 fat tissues with obesity and metabolic disorders and absence of SCD can improve 478 metabolic syndrome in mice (MacDonald et al., 2008). Using ceRNA, we narrowed the 479 targets of mRNAs related to IR and ROS with a IncRNA_miRNA_mRNA network, 480 pointing the way for further studies to verify the genes and describe their function.

481

482

483

484

485

486

487

488

489

490

491

492

493

494

495

496

497

498

499

500

501

502

503

504

505

506

507

508

509

510

511

512

Generally, we believe that biochemical experiments combined with high-throughput technologies could shed new light to explore complex biological mechanisms underlying the efficacy of APBBR. At the same time, the IncRNA played an important role in the IR and could offer new therapeutic targets for IR mechanism research. It is noteworthy that many IncRNAs in the ceRNA network are not annotated, which is quite worth futher study. We hope to inspire researchers to study the role of non-coding RNAs in IR and APBBR treatment.

\section{Conclusions}

In summary, our investigation indicates that attenuated IR in hepG2 cells manifestation by increased cell survival rate and decreased ROS level. Furthermore, we explored the target genes highly enriched in pathways related to ROS and IR and predicted the network regulated by IncRNA according to ceRNA theory, revealing the potential biofunctional roles for IncRNAs as drivers of IR. Transcriptome profiling and regulatory network provides a rationale for exploiting the insulin-sensitizing potential of APBBR by decreasing ROS level via MAPK pathway, which enriches the therapeutic options in the treatment of IR and enhanced our understanding of APBBR. This study provided the expression profile of IncRNAs in IR-hepG2 cells for the first time and laid a foundation for the study on the molecular mechanism of IncRNA regulating IR as well as the followup study on the IncRNA regulating mechanism of APBBR in treating IR.

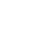

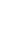

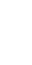

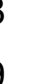

10


513

514

515

516

517

518

519

520

521

522

523

524

525

526

527

528

529

530

531

532

533

534

535

536

537

538

539

540

541

542

543

544

545

546

547

548

549

550

551

552

\section{References}

Li T, Qin Y, Zhen Z, Shen H, Cong T, Schiferle E, Xiao S. 2019. Long non-coding RNA HOTAIR/microRNA-206 sponge regulates STC2 and further influences cell biological functions in head and neck squamous cell carcinoma. Cell proliferation:e12651. DOI: 10.1111/cpr. 12651.

lyer MK, Niknafs YS, Malik R, Singhal U, Sahu A, Hosono Y, Barrette TR, Prensner JR, Evans JR, Zhao S, Poliakov A, Cao X, Dhanasekaran SM, Wu Y-M, Robinson DR, Beer DG, Feng FY, lyer HK, Chinnaiyan AM. 2015. The landscape of long noncoding RNAs in the human transcriptome. Nature genetics 47:199-208. DOI: 10.1038/ng.3192.

Zhang Z, Li J, He T, Ouyang Y, Huang Y, Liu Q, Wang P, Ding J. 2019. The ceRNA regulatory network reveals potential prognostic biomarkers for overall survival in hepatocellular carcinoma. Cancer science. DOI: 10.1111/cas.14138.

Liyanage KIP, Ganegoda GU. 2017. Therapeutic Approaches and Role of ncRNAs in Cardiovascular Disorders and Insulin Resistance. BioMed research international 2017:4078346. DOI: 10.1155/2017/4078346.

Eslam M, Valenti L, Romeo S. 2018. Genetics and epigenetics of NAFLD and NASH: Clinical impact. Journal of hepatology 68:268-279. DOI: 10.1016/j.jhep.2017.09.003.

Williams JF, Olefsky JM. 1990. Defective insulin receptor function in down-regulated HepG2 cells. Endocrinology 127:1706-1717. DOI: 10.1210/endo-127-4-1706.

Li R, Jia Z, Trush MA. 2016. Defining ROS in Biology and Medicine. Reactive oxygen species (Apex, N.C.) 1:9-21. DOI: 10.20455/ros.2016.803.

Newsholme P, Haber EP, Hirabara SM, Rebelato ELO, Procopio J, Morgan D, OliveiraEmilio HC, Carpinelli AR, Curi R. 2007. Diabetes associated cell stress and dysfunction: role of mitochondrial and non-mitochondrial ROS production and activity. The Journal of physiology 583:9-24. DOI: 10.1113/jphysiol.2007.135871.

Liu P, Shi L, Cang X, Huang J, Wu X, Yan J, Chen L, Cui S, Ye X. 2017. CtBP2 ameliorates palmitate-induced insulin resistance in HepG2 cells through ROS mediated JNK pathway. General and comparative endocrinology 247:66-73. DOI:

10.1016/j.ygcen.2017.01.018.

Peer] reviewing PDF | (2019:08:40702:2:0:NEW 4 Jan 2020) 
553

554

555

556

557

558

559

560

561

562

563

564

565

566

567

568

569

570

571

572

573

574

575

576

577

578

579

580

581

582

583

584

585

586

587

588

589

590

591

592
Williams JF, Olefsky JM. 1990. Defective insulin receptor function in down-regulated HepG2 cells. Endocrinology 127:1706-1717. DOI: 10.1210/endo-127-4-1706.

Fu J, Yang Q, Li Y, Li P, Wang L, Li X. 2018. A mechanism by which Astragalus polysaccharide protects against ROS toxicity through inhibiting the protein dephosphorylation of boar sperm preserved at 4 degrees $C$. Journal of cellular physiology 233:5267-5280. DOI: 10.1002/jcp.26321.

Yang,Z.-R. ,2017. The primary study of the compatibility rule in vivo of Coptidis rhizoma based on its hypoglycemic activity. Chengdu University of TCM.

Wang,S.-H.,Wang,W.-J.,Wang,X.-F.,Chen,W.-H.,2019. Effect of Astragalus Polysaccharides and Berberine on Carbohydrate Metabolism and Cell Differentiation in 3T3-L1 Adipocytes. Institute of Integrative Traditional Chinese and Western Medicine.

Mao, Z.-J., Shou,D., Chai, K.-F., 2017. Effects of astragalus polysaccharides and berberine on attenuating insulin resistance in IR-INS-1 cells by down-regulating miR126-3p. China Journal of Traditional Chinese Medicine and Pharmacy.

Burge C, Karlin S. 1997. Prediction of complete gene structures in human genomic DNA. Journal of molecular biology 268:78-94. DOI: 10.1006/jmbi.1997.0951.

Semenkovich CF. 2016. Insulin Resistance and a Long, Strange Trip. The New England journal of medicine 374:1378-1379. DOI: 10.1056/NEJMe1600962.

Archer AE, Von Schulze AT, Geiger PC. 2018. Exercise, heat shock proteins and insulin resistance. Philosophical transactions of the Royal Society of London. Series B, Biological sciences 373. DOI: 10.1098/rstb.2016.0529.

Dontsov A V, Vasil'eva L V. 2016. [INSULIN RESISTANCE ASSOCIATED WITH METABOLIC SYNDROME AS AN INDICATOR OF CARDIOVASCULAR RISK]. Klinicheskaia meditsina 94:189-193.

Seino Y, Nanjo K, Tajima N, Kadowaki T, Kashiwagi A, Araki E, Ito C, Inagaki N, Iwamoto Y, Kasuga M, Hanafusa T, Haneda M, Ueki K. 2010. Report of the committee on the classification and diagnostic criteria of diabetes mellitus. Journal of diabetes investigation 1:212-228. DOI: 10.1111/j.2040-1124.2010.00074.x. 
593 Tan C, Sasagawa Y, Mori M. 2017. The association between insulin resistance,

594

595

596

597

598

599

600

601

602

603

604

605

606

607

608

609

610

611

612

613

614

615

616

617

618

619

620

621

622

623

624

625

626

627

628

629

630

631

632

633

metabolic syndrome, and ischemic heart disease among Rumoi residents. Journal of general and family medicine 18:360-364. DOI: 10.1002/jgf2.94.

Otto GW, Kaisaki PJ, Brial F, Le Lay A, Cazier J-B, Mott R, Gauguier D. 2019. Conserved properties of genetic architecture of renal and fat transcriptomes in rat models of insulin resistance. Disease models \& mechanisms 12. DOI: $10.1242 / \mathrm{dmm} .038539$.

Newsholme P, Cruzat VF, Keane KN, Carlessi R, de Bittencourt PIHJ. 2016. Molecular mechanisms of ROS production and oxidative stress in diabetes. The Biochemical journal 473:4527-4550. DOI: 10.1042/BCJ20160503C.

Chattopadhyay M, Khemka VK, Chatterjee G, Ganguly A, Mukhopadhyay S, Chakrabarti S. 2015. Enhanced ROS production and oxidative damage in subcutaneous white adipose tissue mitochondria in obese and type 2 diabetes subjects. Molecular and cellular biochemistry 399:95-103. DOI: 10.1007/s11010-014-2236-7.

Meex RCR, Blaak EE, van Loon LJC. 2019. Lipotoxicity plays a key role in the development of both insulin resistance and muscle atrophy in patients with type 2 diabetes. Obesity reviews : an official journal of the International Association for the Study of Obesity. DOI: 10.1111/obr.12862.

Keane KN, Cruzat VF, Carlessi R, de Bittencourt PIHJ, Newsholme P. 2015. Molecular Events Linking Oxidative Stress and Inflammation to Insulin Resistance and beta-Cell Dysfunction. Oxidative medicine and cellular longevity 2015:181643. DOI: 10.1155/2015/181643.

Klaunig JE, Wang Z, Pu X, Zhou S. 2011. Oxidative stress and oxidative damage in chemical carcinogenesis. Toxicology and applied pharmacology 254:86-99. DOI: 10.1016/j.taap.2009.11.028.

Valko M, Leibfritz D, Moncol J, Cronin MTD, Mazur M, Telser J. 2007. Free radicals and antioxidants in normal physiological functions and human disease. The international journal of biochemistry \& cell biology 39:44-84. DOI: 10.1016/j.biocel.2006.07.001.

Gonzalez-Menendez P, Hevia D, Alonso-Arias R, Alvarez-Artime A, Rodriguez-Garcia A, Kinet S, Gonzalez-Pola I, Taylor N, Mayo JC, Sainz RM. 2018. GLUT1 protects

Peerj reviewing PDF | (2019:08:40702:2:0:NEW 4 Jan 2020) 
634 prostate cancer cells from glucose deprivation-induced oxidative stress. Redox biology

635

636

637

638

639

640

641

642

643

644

645

646

647

648

649

650

651

652

653

654

655

656

657

658

659

660

661

662

663

664

665

666

667

668

669

670

671

17:112-127. DOI: 10.1016/j.redox.2018.03.017.

Meng F-C, Wu Z-F, Yin Z-Q, Lin L-G, Wang R, Zhang Q-W. 2018. Coptidis rhizoma and its main bioactive components: recent advances in chemical investigation, quality evaluation and pharmacological activity. Chinese medicine 13:13. DOI: 10.1186/s13020-018-0171-3.

Jiang S-J, Dong H, Li J-B, Xu L-J, Zou X, Wang K-F, Lu F-E, Yi P. 2015. Berberine inhibits hepatic gluconeogenesis via the LKB1-AMPK-TORC2 signaling pathway in streptozotocin-induced diabetic rats. World journal of gastroenterology 21:7777-7785. DOI: 10.3748/wjg.v21.i25.7777.

Sun J, Liu Y, Yu J, Wu J, Gao W, Ran L, Jiang R, Guo M, Han D, Liu B, Wang N, Li Y, Huang H, Zeng L, Gao Y, Li X, Wu Y. 2019. Effects of APS Activates Hepatic Insulin Signaling in HFD-induced IR Mice. Journal of molecular endocrinology. DOI: 10.1530/JME-19-0035.

Ma X, Chen Z, Wang L, Wang G, Wang Z, Dong X, Wen B, Zhang Z. 2018. The Pathogenesis of Diabetes Mellitus by Oxidative Stress and Inflammation: Its Inhibition by Berberine. Frontiers in pharmacology 9:782. DOI: 10.3389/fphar.2018.00782.

Han S-S, Kim WJ, Hong Y, Hong S-H, Lee S-J, Ryu DR, Lee W, Cho YH, Lee S, Ryu YJ, Won JY, Rhee H, Park JH, Jang SJ, Lee JS, Choi C-M, Lee JC, Lee S Do, Oh Y-M. 2014. RNA sequencing identifies novel markers of non-small cell lung cancer. Lung cancer (Amsterdam, Netherlands) 84:229-235. DOI: 10.1016/j.lungcan.2014.03.018.

Moran I, Akerman I, van de Bunt M, Xie R, Benazra M, Nammo T, Arnes L, Nakic N, Garcia-Hurtado J, Rodriguez-Segui S, Pasquali L, Sauty-Colace C, Beucher A, Scharfmann R, van Arensbergen J, Johnson PR, Berry A, Lee C, Harkins T, Gmyr V, Pattou F, Kerr-Conte J, Piemonti L, Berney T, Hanley N, Gloyn AL, Sussel L, Langman L, Brayman KL, Sander M, McCarthy MI, Ravassard P, Ferrer J. 2012. Human beta cell transcriptome analysis uncovers IncRNAs that are tissue-specific, dynamically regulated, and abnormally expressed in type 2 diabetes. Cell metabolism 16:435-448. DOI: 10.1016/j.cmet.2012.08.010. 
672 Esguerra JLS, Bolmeson C, Cilio CM, Eliasson L. 2011. Differential glucose-regulation 673 of microRNAs in pancreatic islets of non-obese type 2 diabetes model Goto-Kakizaki 674 rat. PloS one 6:e18613. DOI: 10.1371/journal.pone.0018613.

675

676 Davalos A, Goedeke L, Smibert P, Ramirez CM, Warrier NP, Andreo U, Cirera-Salinas

677 D, Rayner K, Suresh U, Pastor-Pareja JC, Esplugues E, Fisher EA, Penalva LOF,

678

679

680

681

682

683

684

685

686

687

688

689

690

691

692

693

694

695

696

697

698

699

700

701

702

703

704

705

706

707

708

709

710

711 Moore KJ, Suarez Y, Lai EC, Fernandez-Hernando C. 2011. miR-33a/b contribute to the regulation of fatty acid metabolism and insulin signaling. Proceedings of the National Academy of Sciences of the United States of America 108:9232-9237. DOI: 10.1073/pnas.1102281108.

Zeggini E, Weedon MN, Lindgren CM, Frayling TM, Elliott KS, Lango H, Timpson NJ, Perry JRB, Rayner NW, Freathy RM, Barrett JC, Shields B, Morris AP, Ellard S, Groves CJ, Harries LW, Marchini JL, Owen KR, Knight B, Cardon LR, Walker M, Hitman GA, Morris AD, Doney ASF, McCarthy MI, Hattersley AT. 2007. Replication of genome-wide association signals in UK samples reveals risk loci for type 2 diabetes. Science (New York, N.Y.) 316:1336-1341. DOI: 10.1126/science.1142364.

Phelps M, Coss C, Wang H, Cook M. 2016. Registered report: Coding-independent regulation of the tumor suppressor PTEN by competing endogenous mRNAs. eLife 5. DOI: $10.7554 /$ eLife.12470.

Ling H-Y, Ou H-S, Feng S-D, Zhang X-Y, Tuo Q-H, Chen L-X, Zhu B-Y, Gao Z-P, Tang C-K, Yin W-D, Zhang L, Liao D-F. 2009. CHANGES IN microRNA (miR) profile and effects of miR-320 in insulin-resistant 3T3-L1 adipocytes. Clinical and experimental pharmacology \& physiology 36:e32-9. DOI: 10.1111/j.1440-1681.2009.05207.x.

Barr FA, Sillje HHW, Nigg EA. 2004. Polo-like kinases and the orchestration of cell division. Nature reviews. Molecular cell biology 5:429-440. DOI: 10.1038/nrm1401.

Zhang N, Li H, Liu J, Yang W. 2014. Gene expression profiles in zebrafish (Danio rerio) liver after acute exposure to okadaic acid. Environmental toxicology and pharmacology 37:791-802. DOI: 10.1016/j.etap.2014.02.005.

Zhou M-M, Zhang W-Y, Li R-J, Guo C, Wei S-S, Tian X-M, Luo J, Kong L-Y. 2018. Antiinflammatory activity of Khayandirobilide A from Khaya senegalensis via NF-kappaB, AP-1 and p38 MAPK/Nrf2/HO-1 signaling pathways in lipopolysaccharide-stimulated RAW 264.7 and BV-2 cells. Phytomedicine : international journal of phytotherapy and phytopharmacology 42:152-163. DOI: 10.1016/j.phymed.2018.03.016. 
712

713 Ushio-Fukai M, Alexander RW. 2004. Reactive oxygen species as mediators of

714 angiogenesis signaling: role of $\mathrm{NAD}(\mathrm{P}) \mathrm{H}$ oxidase. Molecular and cellular biochemistry

715 264:85-97.

716

717 MacDonald MLE, Singaraja RR, Bissada N, Ruddle P, Watts R, Karasinska JM, Gibson

718 WT, Fievet C, Vance JE, Staels B, Hayden MR. 2008. Absence of stearoyl-CoA

719 desaturase-1 ameliorates features of the metabolic syndrome in LDLR-deficient mice.

720 Journal of lipid research 49:217-229. DOI: 10.1194/jlr.M700478-JLR200.

721

722

723

724

725

726

727

728

729

730

731

732

733

734

735

736

737

738

739

740

741

742

743

744

745

746

747

748

749

750

\section{Figure Legends:}

Fig.1. Glucose concentration of HepG2 cells (A). Survival rate of HepG2 cells (B) The ROS content in HepG2 cells $(\mathrm{C})$

${ }^{\Delta 4} P<0.01$,compared with those in the control group; ${ }^{* *} P<0.01$ compared with that of the model group.

Fig.2. Expression profiles of mRNAs in experimental groups. Differential mRNA expression profile(A). Volcano plot depicting DEGs (B,C). Heatmap for DEGs(D,E). GO analysis results for DEGs(F,G). KEGG pathway analysis for DEGs (I).

Fig.3. Differentially expressed lncRNAs in experimental groups. Circos plots showing all of the lncRNAs in experimental groups (A). Differential lncRNA expression profile(B). Volcano plot depicting $\operatorname{lncRNAs}(C, D)$. Heatmap for differentially expressed lncRNAs (E,F). Venn diagrams show overlaps of differentially expressed lncRNAs between experimental groups $(\mathrm{G}, \mathrm{H})$. Two lncRNAs decreased in Model group but increased in APBBR group. Five lncRNAs increased expression in Model group but decreased in APBBR group.

Fig.4. Comparative characteristics analysis of mRNAs and lncRNAs. Expression level of mRNA and $\operatorname{lncRNA}(\mathrm{A}, \mathrm{B})$. length distribution of $\mathrm{mRNA}$ and $\operatorname{lncRNA}(\mathrm{C})$. Exon number of mRNA and lncRNA(D). ORF length distribution of mRNA and $\operatorname{lncRNA}(\mathrm{E}, \mathrm{F})$

Fig.5. Interaction network of differentiated lncRNA-miRNA-mRNA in normal, IR and APBBR-treated HepG2 cells. Rectangle, triangle and ellipse represent miRNA, lncRNA and mRNA respectively. This genes figure are showed genes belonging to the same trend.( increasedecrease type/decrease-increase type).In the lncRNA-miRNA-mRNA predicted interaction network, 30 miRNAs are predicted to be possible target genes for regulating them. 
751

752 
Figure 1

Study on the effect of IR-hepG2 cell phenotype

Glucose concentration of HepG2 cells (A). Survival rate of HepG2 cells (B).The ROS content in HepG2 cells $(C) .{ }^{\Delta} P<0.05$ and ${ }^{\Delta \Lambda} P<0.01$, compared with those in the control group; ${ }^{*} P<$ 0.05 and $^{* *} P<0.01$ compared with that of the model group.

A

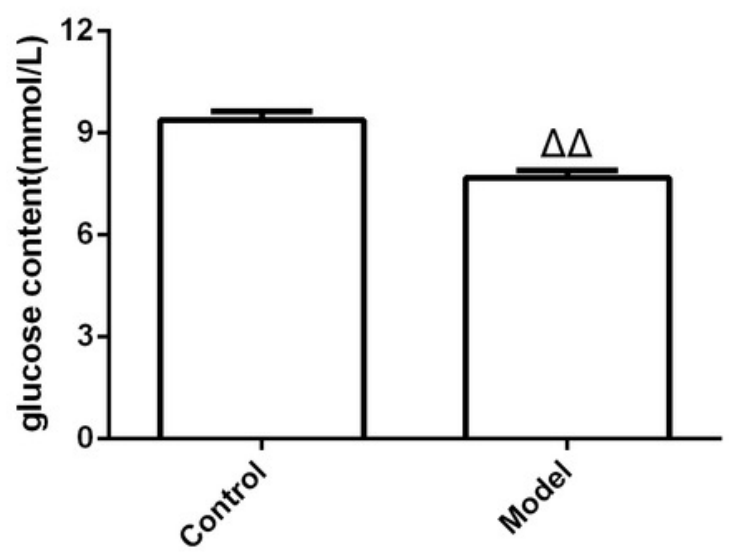

C

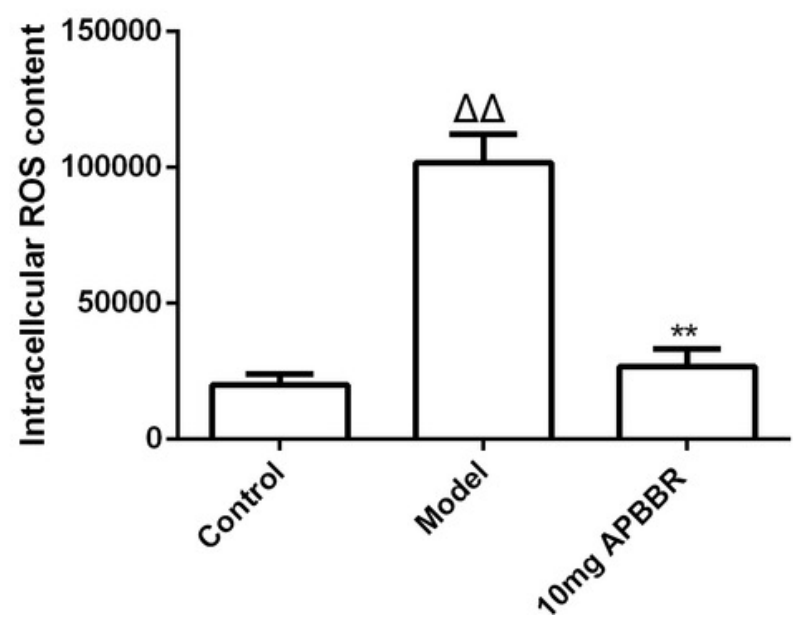

B

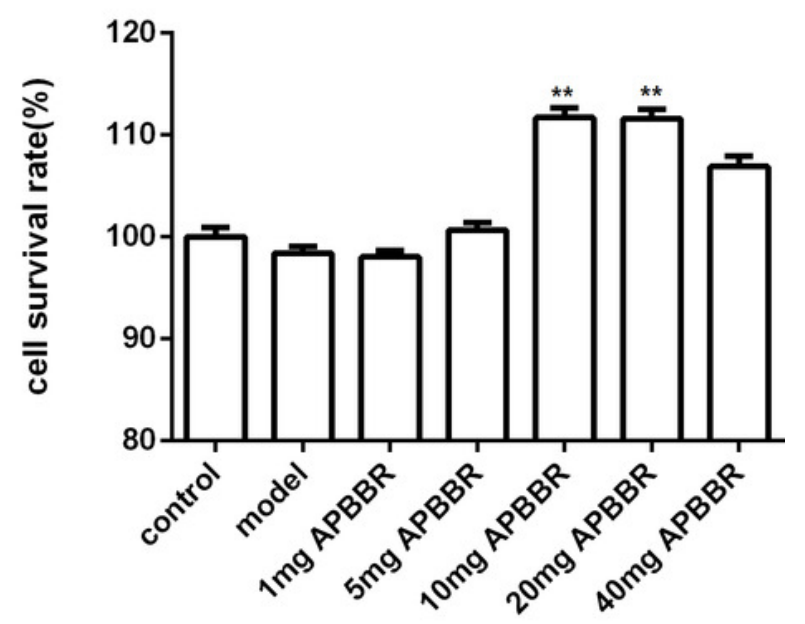


Figure 2

Expression profiles of mRNAs in experimental groups.

Expression profiles of mRNAs in experimental groups. Differential mRNA expression profile(A). Volcano plot depicting DEGs (B,C). Heatmap for DEGs(D,E). GO analysis results for $\operatorname{DEGs}(\mathrm{F}, \mathrm{G})$. KEGG pathway analysis for DEGs (I). 

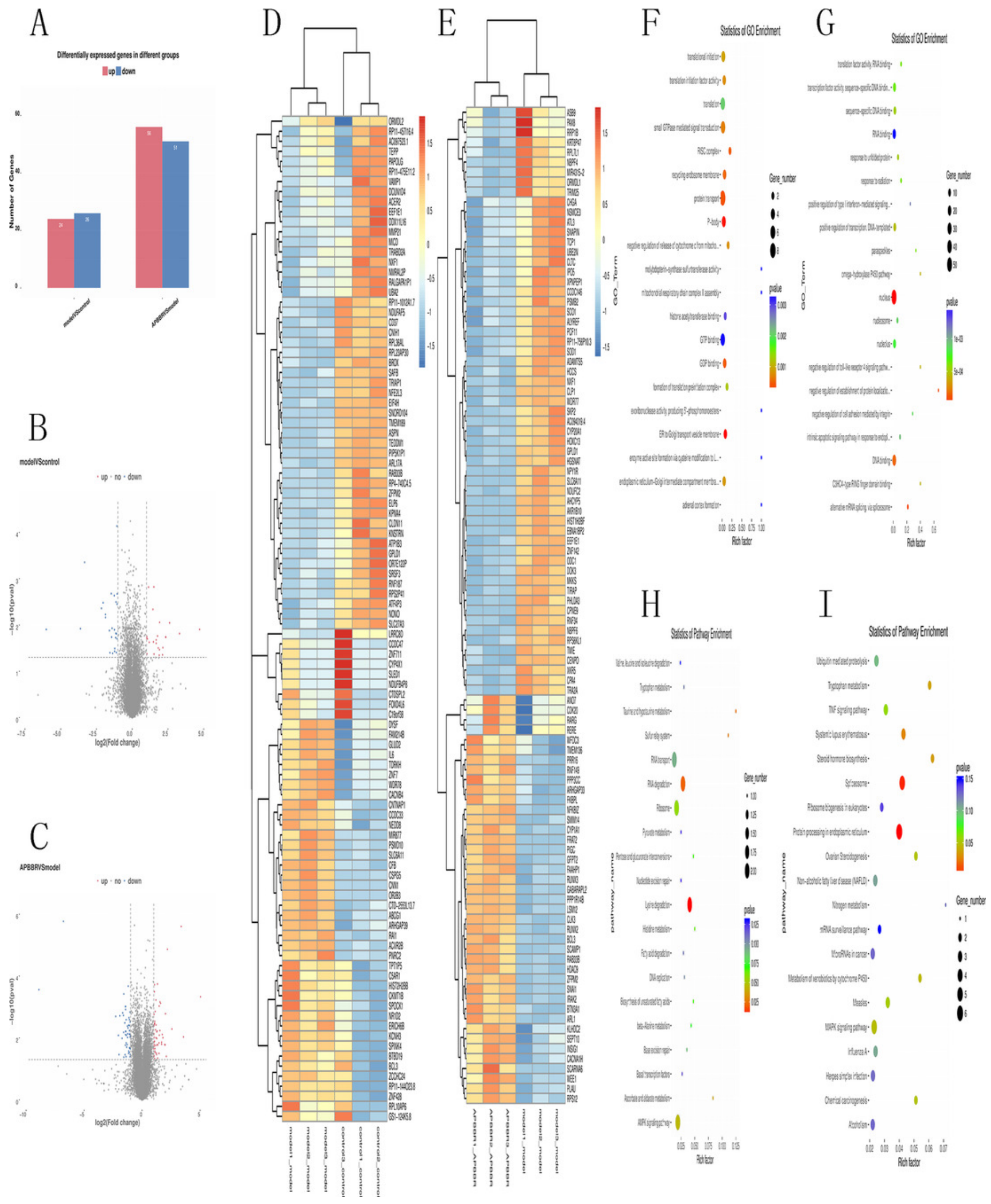


\section{Figure 3}

Differentially expressed IncRNAs in experimental groups.

Circos plots showing all of the IncRNAs in experimental groups (A). Differential IncRNA expression profile(B). Volcano plot depicting IncRNAs(C,D). Heatmap for differentially expressed IncRNAs $(E, F)$. Venn diagrams show overlaps of differentially expressed IncRNAs between experimental groups $(\mathrm{G}, \mathrm{H})$. Two IncRNAs decreased in Model group but increased in APBBR group. Five IncRNAs increased expression in Model group but decreased in APBBR group. 

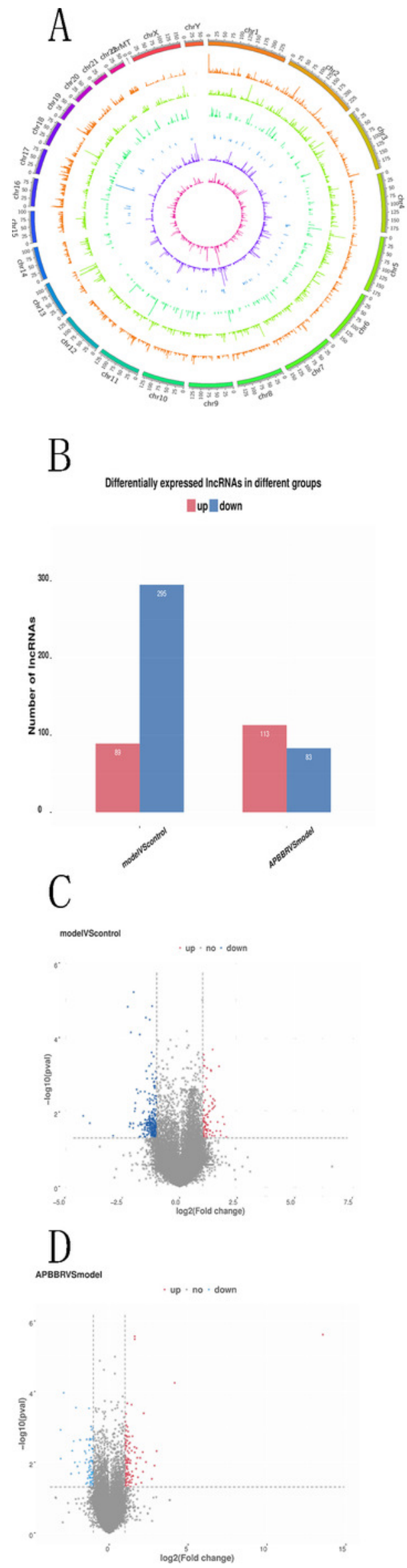

Peer) reviewing PDF | (2019:08:40702:2:0:NEW 4 Jan 2020)
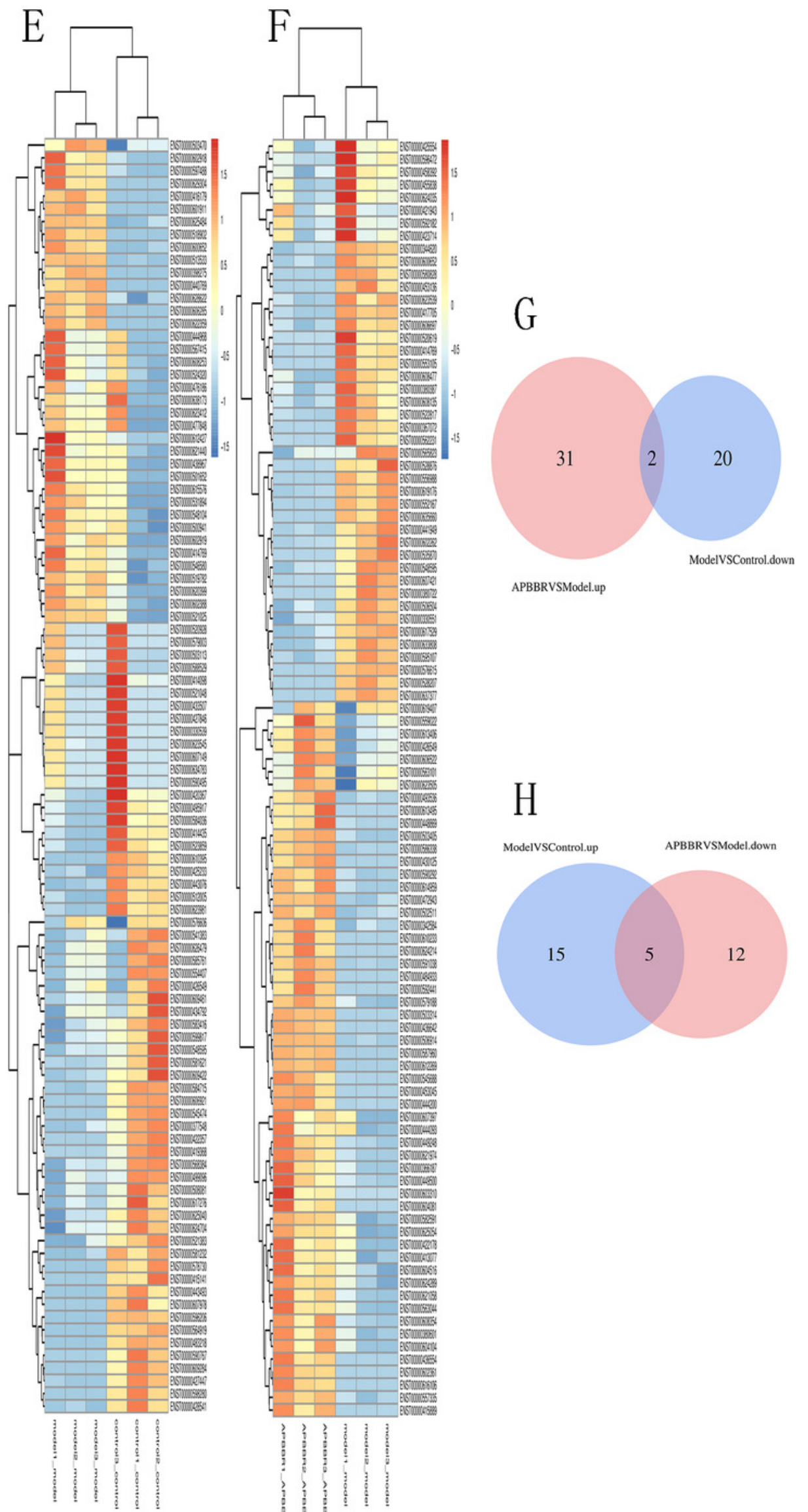

APBBRVSModel.up
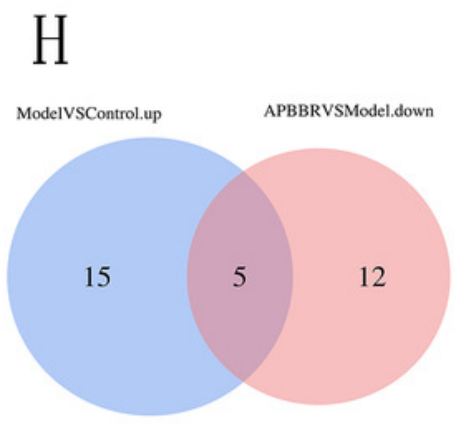
Figure 4

Comparative characteristics analysis of mRNAs and IncRNAs.

Comparative characteristics analysis of mRNAs and IncRNAs. Expression level of mRNA and IncRNA $(A, B)$. length distribution of mRNA and InCRNA(C). Exon number of mRNA and IncRNA(D). ORF length distribution of $m R N A$ and IncRNA(E,F) 

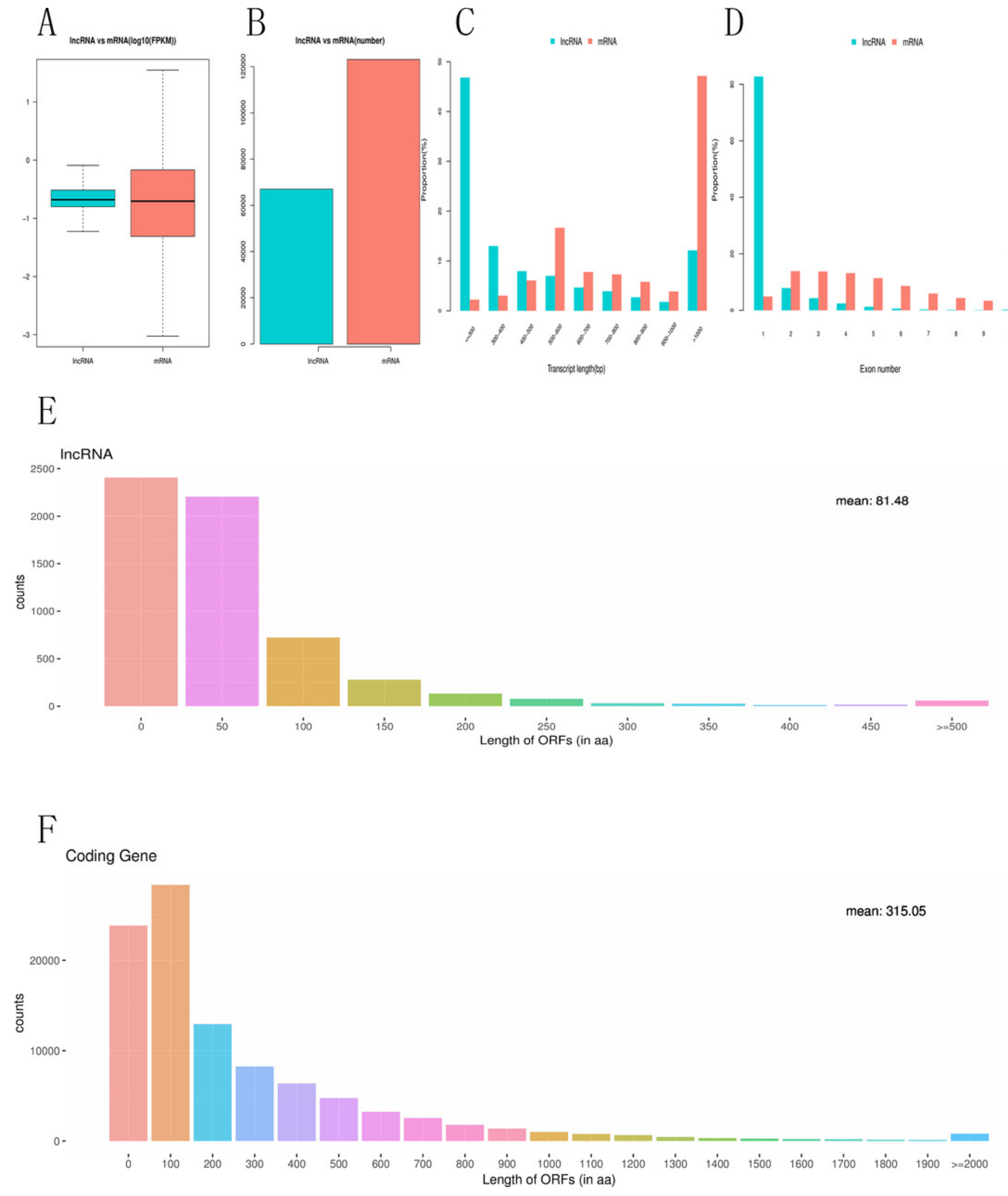


\section{Figure 5}

Interaction network of differentiated IncRNA-miRNA-mRNA in normal, IR and APBBRtreated HepG2 cells.

Rectangle, triangle and ellipse represent miRNA, IncRNA and mRNA respectively. This genes figure are showed genes belonging to the same trend.( increase-decrease type/decreaseincrease type).In the IncRNA-miRNA-mRNA predicted interaction network, 30 miRNAs are predicted to be possible target genes for regulating them.

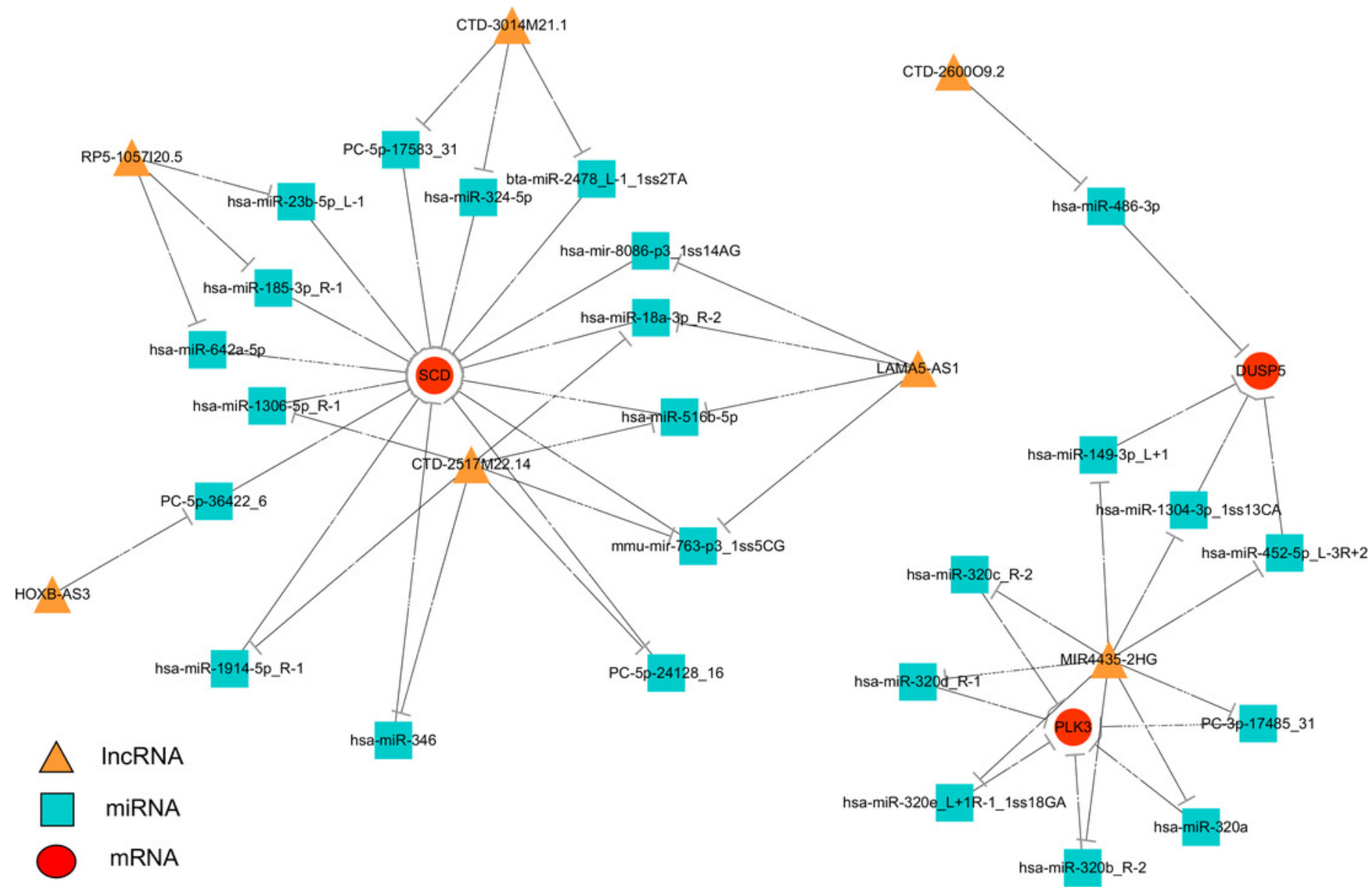

